\title{
Bos Indicus-Cross Feedlot Cattle with Excitable Temperaments have Tougher Meat and a Higher Incidence of Borderline Dark Cutters
}

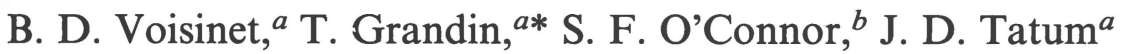 \\ \& M. J. Deesing ${ }^{a}$ \\ ${ }^{a}$ Department of Animal Sciences, Colorado State University, Fort Collins, CO 80523, USA \\ ${ }^{b}$ Gerber Agri., Inc., 650 S. Cherry St. Suite 600, Denver, CO 80222, USA
}

(Received 22 November 1996; revised version received 14 March 1997; accepted 14 March 1997)

\begin{abstract}
Temperament ratings based on a numerical scale (chute score) were assessed during weighing and handling of cattle at a feedlot. Breeds studied included Braford, Red Brangus and Simbrah. Cattle were fed to a constant fat thickness of 9 to $13 \mathrm{~mm}$ (target $=11 \mathrm{~mm}$ ) over the 12th rib as determined by periodic ultrasound measurements. Cattle were slaughtered in a commercial slaughter plant and stunned by captive bolt. Temperament rating had a significant effect on the incidence of borderline dark cutters which were downgraded by a USDA grader $(\mathrm{P}=0.01)$. Temperament score also had a significant effect on tenderness $(\mathbf{P}<0.001)$ as evaluated by Warner-Bratzler Shear $(W B S)$ force at day 14 post mortem. The calmest animals which stood still when restrained in a hydraulic squeeze chute had a mean WBS force of $2.86 \pm 11 \mathrm{~kg}$ and cattle which became highly agitated and struggled violently during restraint averaged $3.63 \pm 19 \mathrm{~kg}$. Forty percent of these cattle had WBS force values which were over $3.9 \mathrm{~kg}$ which is a threshold value for acceptability in food service establishments. These data show that cattle with the most excitable temperament ratings produce carcasses with tougher meat and a higher incidence of borderline dark cutters than cattle with calm temperament ratings. (C) 1997 Elsevier Science Ltd
\end{abstract}

\section{INTRODUCTION}

Meat quality issues, such as tenderness and dark cutting, currently concern the beef industry. A survey of purveyors, restaurateurs and retailers ranked both of these defects in the top 10 primary concerns about the quality of beef (Smith et al., 1992). Dark cutting carcasses and inadequate beef palatability were responsible for losses of $\$ 5.00$ and $\$ 2.89$ per head, respectively (Smith et al., 1992).

Previous studies have shown that there is a relationship between the dark cutting condition and animal behavior. Several studies have shown that mixing strange cattle together results in fighting, mounting and other physical activity that increases the incidence of dark

*To whom correspondence should be addressed. 
cutting (Grandin, 1980; Tennessen and Price, 1980; Kenny and Tarrant, 1987). It has been well established that physical stress results in glycogen depletion which will result in dark cutting meat if it occurs prior to slaughter (Ashmore et al., 1973; McVeigh et al., 1982). However, absolute causes of the dark cutting condition have not yet been established, and a means of identifying animals that may be more susceptible to dark cutting does not exist.

Objective scoring of animals' behaviors while subjected to potentially stressful conditions, such as restraining in a squeeze chute, have been used to assess cattle temperament (Tulloh, 1961; Fordyce et al., 1988; Gonyou et al., 1986). Temperament, which has been shown to be moderately heritable in cattle (Shrode and Hammack, 1971; Stricklin et al., 1980; Hearnshaw and Morris 1984; Fordyce et al., 1988), generally means the excitability or the tendency of an animal to become agitated when it is handled. Temperament rankings, or chute scores, can give an indication of the amount of active resistance exhibited by an animal when it is restrained for routine, non-painful husbandry procedures such as vaccinations. Grandin (1993) and Lyons (1989) reported that the degree of behavioral agitation expressed by animals during routine handling procedures is consistent over multiple handling experiences. However, Crookshank et al. (1979) reported that, in cattle, agitation and cortisol levels decreased with subsequent experiences in the handling facility because the cattle became habituated. Hargreaves and Hutson (1990) likewise have shown that getting sheep accustomed to people and reducing their flight zone is somewhat successful at reducing aversion to repeated handling procedures. Regardless of the changes in aversion that a single animal exhibits over time, we would expect behavioral changes to remain relatively consistent with respect to its contemporaries.

Temperament has been shown to be related to various aspects of livestock production, such as milk production (Drugociu et al., 1977; Lyons, 1989) and daily weight gain (Voisinet et al., 1997). Stricklin et al. (1980) and Voisinet et al. (1997) both found that heifers had a more excitable temperament than steers. The objective of this study was to investigate the impact of temperament on the incidence of dark cutters and toughness in cattle slaughtered in a large commercial slaughter plant.

\section{MATERIALS AND METHODS}

\section{Animals and management}

Three hundred and six cattle (7-11 months old), comprised of steers $(n=162)$ and heifers $(n=144)$, were transported from Florida to feedlot facilities in Colorado for finishing after 45 days of backgrounding in Oklahoma. Breeds studied included Braford (3/8 Brahman $\times 5 / 8$ Hereford or $1 / 2$ Brahman $\times 1 / 2$ Hereford), Red Brangus (3/8 Brahman $\times 5 / 8$ Red Angus or 1/4 Brahman $\times 3 / 4$ Red Angus) and Simbrah (3/8 Brahman $\times 5 / 8$ Simmental). Cattle were housed in groups of approximately 20 to 50 head, with group allotments determined by gender and weight after a 2 week acclimation period.

All cattle received a concentrated diet consisting primarily of whole corn and corn silage [for a complete description of the diet, see O'Connor et al. (1997)]. Growth implants were administered at the start of the finishing period and after approximately 120 days on feed. Implant protocols were as follows: steers were given an initial implant containing $200 \mathrm{mg}$ of progesterone and $20 \mathrm{mg}$ of estradiol benzoate, and a second implant containing $120 \mathrm{mg}$ of trenbolone acetate and $24 \mathrm{mg}$ of estradiol; heifers received $200 \mathrm{mg}$ of trenbolone acetate for both the initial and the second implants. Heifers were supplemented with $0.4 \mathrm{mg}$ per animal per day melengestrol acetate (MGA) for the duration of the feeding period. No withdrawal of MGA was utilized prior to slaughter. Cattle were fed to acquire a constant subcutaneous fat thickness of 9 to $13 \mathrm{~mm}$ (target $=11 \mathrm{~mm}$ ) over the $12 \mathrm{th}$ rib, as 
determined by visual indices and ultrasound measurements. Growth traits, such as initial and final test weights and average daily gains for a population of cattle that includes the present sample population, are reported in Voisinet et al. (1997).

\section{Experimental procedures}

Animals were temperament rated once, by a single observer during initial test weight determination which occurred after a 2 week acclimation period to feedlot conditions. Temperament scores were recorded the first time animals were handled in the feedlot working facilities. Temperament rating was conducted while each animal was restrained in a hydraulic squeeze chute (crush). The squeeze chute holds the animal by pressing on its body with side squeeze panels and holding its head in a neck stanchion. Animals were assigned temperament scores based on a 4-point system similar to that used by Grandin (1993). Grandin (1993) found that a series of temperament scores were stable over time for the very calmest animals and for the most excitable animals, when four temperament scores were recorded 30 days apart. Behaviors corresponding to each temperament score were; 1 = 'calm, little movement', 2 = 'squirming, occasional shaking of restraint device', $3=$ 'continuous vigorous movement and shaking of restraint device', $4=$ 'frenzied, rearing, twisting or violently struggling'.

\section{Carcass data collection and sampling procedures}

Animals were sorted into slaughter groups approximately $12-18 \mathrm{hr}$ before slaughter, based on ultrasound measurements and visual appraisal of fatness. The cattle were comingled from different groups the night prior to slaughter. They were slaughtered at a large commercial beef slaughter plant in groups of approximately 40 to 60 head, using conventional industry procedures and captive bolt stunning. Split carcass sides were electrically stimulated, approximately $40 \mathrm{~min}$ after stunning. Carcasses were spray-chilled at $-3^{\circ} \mathrm{C}$ for the first 9 to $11 \mathrm{hr}$; for the remainder of the $24 \mathrm{hr}$ chill period, the cooler was set at $1^{\circ} \mathrm{C}$. The incidence of dark cutting and downgrading owing to color was determined by visual assessment, $24 \mathrm{hr}$ post mortem. Visual assessment was carried out using. a USDA grader per normal industry practice. Dark cutting was scored for severity in units corresponding to quality grade discounts (USDA, 1989), with no discount, 1/3, 2/3, and full grade discounts possible.

Immediately after collection of carcass grade information, a strip loin (USDA, 1988) was obtained from a randomly selected side of each carcass. Strip loins were fabricated into steaks $2.5 \mathrm{~cm}$ thick. Steaks, trimmed of external fat and peripheral connective tissue, were vacuum-packaged and aged for 14 days. After aging the steaks were frozen. Steaks were thawed for $24 \mathrm{hr}$ at $2^{\circ} \mathrm{C}$, then broiled at a setting of 8 on a Hobart Char Broiler (Model CB 51, Hobart Corp., Troy, Ohio, USA). Steaks were turned at 4, 8, 11 and if necessary, 14 min to allow for uniform cooking until the desired internal temperature of $70^{\circ} \mathrm{C}$ was attained. Following cooking, steaks were cooled until they had equilibrated to room temperature and, then, four to eight cores $(1.27 \mathrm{~cm}$ in diameter) were removed parallel to the muscle fiber orientation. A single, peak shear force measurement was recorded for each core using a Warner-Bratzler shear machine; measurements for cores from the same steak were averaged to obtain a single shear force value for each steak.

\section{Statistical analysis}

Data were analyzed using the SAS GLM procedure (SAS, 1985). Incidence of darkcolored lean $(0,1)$ and shear force data were analyzed using least square analysis of 
variance with a model which included breed, gender, temperament and the random effect of sire nested within breed; adjusted fat thickness was used as a covariate. Least-squares means were calculated for temperament, breed, gender and Warner-Bratzler shear force, where appropriate. Frequency data were tested for significance using the chi-square statistic. Slaughter day was not included in the final analysis because it had no effect. There were 14 separate slaughter days and the different cattle breeds and sexes were evenly distributed across the days.

\section{RESULTS}

\section{Temperament effects on meat quality}

Chi-square analysis of the frequency of lean color category reveals that a higher proportion of carcasses which exhibited borderline dark cutting were from the more excitable animals $(P=0.01)$ (Table 1$)$. In carcasses from animals which received a calm temperament rating, (a score of 1) $6.7 \%$ exhibited borderline dark cutting whereas $25 \%$ of the carcasses from highly excitable animals, (a score of 4) exhibited borderline dark cutting $(P<0.05)$. The ultimate $\mathrm{pH}$ of all carcasses ranged from 5.35 to 5.79.

Temperament was also associated with differences in tenderness as measured by Warner-Bratzler shear force $(P<0.001)$ on day 14 of the aging period. As temperament increased from calm to excitable, WBS increased (Table 2). Temperament had a significant effect on toughness when the effect of sex was removed from the analysis.

Chi-square analyses of tenderness, by dividing shear force into two categories, (WBS $<3.9 \mathrm{~kg}$ and WBS $>3.9 \mathrm{~kg}$ ) shows that tenderness is affected by temperament ranking, $(P<0.001)$. A much higher percentage $(40 \%)$ of animals which had very excitable temperaments, or a ranking of 4 , produced steaks with WBS values $>3.9 \mathrm{~kg}$ when compared with temperament ranking categories 1 through 3 , which average only $13.7 \%$ steaks with WBS values $\geq 3.9 \mathrm{~kg}$ (Table 2). The threshold value for acceptability in food service establishments is $3.9 \mathrm{~kg}$ (Shackelford et al., 1991). Steaks with higher shear force values are more likely to be perceived as tough by a trained sensory panel.

\section{Breed effects on meat quality}

Temperament was not different between breeds. Least squares means for temperament score by breed were as follows: Braford $=1.99 \pm 0.12$, Brangus $=2.18 \pm 0.17$, Simbrah $=1 \cdot 14 \pm 0 \cdot 13$. Breed was not related to differences in tenderness in this population of cattle. Previous studies which have examined breed effects on tenderness often have found that $B$. indicus cattle tend to have tougher meat than B. taurus cattle (Johnson et al., 1990;

TABLE 1

Numbers of Animals in Each Temperament Ranking, Separated by Lean Color Category

\begin{tabular}{lccc}
\hline Temperament ranking $^{a}$ & Normal lean & Dark lean & Dark lean, $\%$ \\
\hline 1 & 84 & 6 & $6 \cdot 7^{b}$ \\
2 & 115 & 5 & $4 \cdot 2^{b}$ \\
3 & 70 & 6 & $7 \cdot 9^{b}$ \\
4 & 15 & 5 & $25 \cdot 0^{c}$ \\
\hline
\end{tabular}

${ }^{a} 1=$ calm, little movement; $4=$ frenzied, rearing, twisting or violently struggling.

$b, c$ Percentages values in a column with unlike superscripts are different $(P<0.05)$. 
TABLE 2

Least Square Means For Warner-Bratzler Shear Force For Each Temperament Category

\begin{tabular}{lrcc}
\hline Temperament ranking $^{a}$ & \multicolumn{1}{c}{$n$} & ${\text { Warner-Bratzler shear force, } \mathrm{kg}^{b}}$ & $\%$ of WBS values $\geq 3.9 \mathrm{~kg}$ \\
\hline 1 & 90 & $2 \cdot 86 \pm 0.11^{c}$ & $11 \cdot 1^{c}$ \\
2 & 120 & $2 \cdot 88 \pm 0.09^{c}$ & $9 \cdot 2^{c}$ \\
3 & 76 & $3 \cdot 19 \pm 0.11^{d}$ & $23 \cdot 7^{d}$ \\
4 & 20 & $3 \cdot 63 \pm 0.19^{c}$ & $40.0^{d}$ \\
\hline
\end{tabular}

${ }^{a} 1=$ calm, little movement; $4=$ frenzied, rearing, twisting, or violently struggling.

${ }^{b}$ Values are means $\pm \mathrm{SE}$.

${ }^{c, d}$ Means, within each main effect, with unlike superscripts are different $(P<0.05)$.

Whipple et al., 1990). However, no Warner-Bratzler shear force difference among $1 / 2$ and 3/4 blood Brahman-influenced cattle were reported by Johnson et al. (1990).

Likewise, breed was not associated with the incidence of borderline dark cutting. Prior research is inconsistent with respect to breed susceptibility to dark cutting. Much higher than normal incidence of dark cutting $(50 \%)$ was reported in Guernsey dairy cows (Grandin, 1980). However, Grandin (1979) concluded that breeds of Bos taurus beef cattle had no effect on the occurrence of dark cutters. Shackelford et al. (1994) reported that breed differences did exist between lean color of carcasses from different sire lines. Carcasses from Chianina-cross sires exhibited darker-colored lean than most other breed groups in the study (Shackelford et al., 1994). No differences in the frequency of dark cutting carcasses existed between carcasses produced from Bos indicus sire lines and Bos taurus sire lines (Shackelford et al., 1994). Stress susceptibility manifested in quality problems, specifically pale, soft, exudative meat, has been shown to be at least somewhat breed dependent in swine (Addis, 1986). Research by Tyler et al. (1982) showed that Bos indicus-cross cattle were less stress-susceptible than purebred Hereford and Shorthorn steers.

\section{GENDER EFFECTS ON MEAT QUALITY}

In this population of cattle, temperament was significantly associated with gender $(P<0.05)$ (see also Voisinet et al., 1997). Least square means for temperament score show that heifers are significantly more excitable than steers $(2.23 \pm 0.10$ versus $1.98 \pm 0 \cdot 10$, respectively). Stricklin et al. (1980) found similar gender differences in Bos taurus cattle; however, other research identified only trends in temperament differences (Tulloh, 1961; Shrode and Hammack, 1971).

Analysis of variance also showed that gender was associated with the incidence of borderline dark cutting $(P<0.01)$ and with tenderness as measured by WBS $(P<0.001)$ at day 14 post mortem (Table 3 ). Heifers had significantly tougher meat and a higher incidence of borderline dark cutters than their steer contemporaries. In the present study, however, gender was completely confounded by implant protocol as was described in the Materials and Methods section. The mean WBS force for heifers was $3.25 \pm 0.09 \mathrm{~kg}$ and steers ware $3.04 \pm 0.10 \mathrm{~kg}$.

\section{DISCUSSION}

The animals with the most excitable temperament exhibited more borderline dark cutting and tougher meat (Tables 1 and 2). Even though these borderline dark cutters did not 
TABLE 3

Gender Frequencies in. Each of the Tenderness and Lean Color Categories

\begin{tabular}{lccccccc}
\hline Gender & Mean temperament & \multicolumn{2}{c}{ WBS shear force determination } & \multicolumn{3}{c}{ Color of lean } \\
& score & $<3.9 \mathrm{~kg}$ & $>3.9 \mathrm{~kg}$ & $\%>3.9 \mathrm{~kg}$ & Normal & Dark $\%$ dark \\
\hline Heifers & $2.23 \pm 0.10$ & 111 & 33 & $22.9^{a}$ & 128 & 16 & $11 \cdot 1^{c}$ \\
Steers & $1.98 \pm 0.10$ & 148 & 14 & $8.6^{b}$ & 156 & 6 & $3.7^{d}$ \\
\hline
\end{tabular}

$a, b$ Percentages with unlike superscripts are different $(P<0.001)$.

${ }^{c, d}$ Percentages with unlike superscripts are different $(\mathrm{P}<0.01)$.

have a high enough $\mathrm{pH}$ to be considered true dark cutters, they cost the beef industry millions of dollars in USDA downgrades. Wulf et al. (1997) reported that colorimeter readings from this same group of cattle indicated that the individuals with the darker colored lean had a higher percentage of animals with tough meat. We reason that those animals with the most excitable temperaments may be most susceptible to stress generated by routine handling practices, such as handling and transport, which occur just prior to slaughter. Lawrie (1958) reported that 'excitable' animals had reduced glycogen reserves, and hypothesized that a short range muscular tension, similar to shivering, independent of movement, such as walking or running, may have resulted in the low glycogen reserves which ultimately caused dark cutting. Thus, it follows that dark cutting is more prevalent in the US in the spring and fall (Lawrie, 1958; Tarrant, 1981). During these periods of the year large day/night fluctuations in temperature are likely to occur, and so shivering is also more likely to occur. Selye (1936) found that stress, regardless of the cause, (emotional excitement, cold, fatigue, etc.) resulted in adrenaline release from the adrenal cortex. Adrenaline, through a series of biochemical changes indirectly catalyzes the breakdown of glycogen ante mortem, leading to an elevated muscle ultimate $\mathrm{pH}$ post mortem. It has been well established that pronounced ante mortem glycolysis may result in an elevation in the ultimate $\mathrm{pH}$ of muscles which is primarily responsible for enhancement of the dark cutting condition (Ashmore et al., 1973; McVeigh and Tarrant, 1981; Kenny and Tarrant, 1987). Lawrie (1958) reasoned that if an 'excitable' animal was deficient in the production of glucocorticoids, which normally provide a positive feedback to illicit increased glycogen synthesis, a chronically low level of muscle glycogen may be maintained. This chronic glycogen shortage could occur via genetic deficiencies in the pituitary or hypersensitivity of the hypothalamus, and thus over-stimulation of the pituitary (Lawrie, 1958). Thus, when stress susceptible animals undergo additional stress, they would be more likely than a normal animal to exhibit elevated muscle $\mathrm{pH}$ and dark cutting. Stress susceptibility in these cattle must not be confused with Porcine Stress Syndrome (PSS) (malignant hyperthermia). Stressors appear to be additive (Bray et al., 1989) so that multiple stressors will result in a greater elevation of ultimate muscle $\mathrm{pH}$ than a single stressor alone. Thus, it is conceivable that additional stressors near the time of slaughter, such as handling, sorting, transporting and (or) novel environments would provide sufficient stress levels to produce dark cutting in moderately stress susceptible animals.

Dark cutting is much more prevalent, 11 to $15 \%$ (Tarrant, 1981) in young bulls. Although circulating testosterone may play a role in determination of fiber types (Ashmore, 1974), the increased incidence of dark cutting is predominately attributed to enhanced muscle glycogen depletion. Bulls are known for increased aggressive and sexual activity (Tarrant, 1981) culminating in considerably more mounting behaviors and fighting when co-mingled than normally seen on other gender classes (steers, heifers). Dark cutting has also been shown to increase in heifers which are exhibiting mounting behaviors near the time of estrus (Kenny and Tarrant, 1988). 
Direct evidence exists for the relationship between physical stress and glycogen depletion. Dark cutting can be produced selectively in muscles owing to physical activity, for example mounting characteristically seen in aggressive and sexual behaviors. Mounting behavior in cattle resulted in elevated muscle $\mathrm{pH}$ most extensively in the hind quarter muscle while approximately normal pH was observed in forequarter muscles (Tarrant and Sherington, 1980).

Considerable research has shown that variations exist in muscle glycolysis rates among differing fiber types (Lacourt and Tarrant, 1985; Rao and Gault, 1989). Muscles composed predominately of 'white' (fast twitch) fiber types will typically have a lower glycogen content after mixing stress (Lacourt and Tarrant, 1985). 'Red' (slow twitch) muscle fibers appear to have a greater affinity for circulating adrenaline and thus undergo more extensive glycogen depletion during stress induced by exogenous adrenaline (Lacourt and Tarrant, 1985). Research by Rao and Gault (1989) in muscles from unstressed animals, however, found that predominately 'red' fiber type muscles had a higher ultimate $\mathrm{pH}$ than did 'white' fiber type muscles. Data reviewed by Young and Foote (1984) suggested that muscles which are low in glycolytic capacity and high in oxidative capacity are less prone to dark cutting. Young and Foote (1984) found that muscles with a high proportion of primarily glycolytic fibers appeared to exhibit an increased propensity for dark cutting. However, they also found this fiber type to be more common in bulls which usually exhibit more dark cutting. To the author's knowledge no formal research has been completed which addresses a possible temperament-fiber type relationship.

A study by Zerouala and Strickland (1991) draws connections between factors which are known to produce changes in fiber type in controlled conditions, such as temperature, genetics and carcass weight, and those factors identified as contributing to an increased incidence of dark cutting. Ashmore (1974) theorized that muscle susceptibility to stress (in a biochemical sense) is determined by the proportion of fibers with glycolytic metabolism. His primary line of reasoning is that metabolically, glycolytic fibers have an enhanced response to epinephrine (Ashmore, 1974). Epinephrine causes glycolysis to increase in muscle fibers and thus an increase in lactic acid results prior to slaughter. Some research with 'double muscled' cattle supports this hypothesis. Experiments in Angus cattle which exhibited muscle hypertrophy shows that these animals exhibit an increased number of glycolytic fibers (Holmes et al., 1972). Research has also shown that animals which exhibit muscle hypertrophy also had an enhanced glycolytic capacity and a higher blood lactate level (Holmes et al., 1972, 1973). In addition to exhibiting altered biochemical and physiological characteristics, 'double muscled' cattle have also been known to exhibit a more excitable temperament (Homes et al., 1972). These findings may be explained, at least in part, by research by Pitts (1971). Pitts found that 'anxiety neurosis' in man, characteristics of which include nervousness and intense fear, can be produced by an increased level of blood lactate. As mentioned above, an increase in blood lactate is also seen in 'double muscled' cattle (Holmes et al., 1972).

It has been well established that muscle color is highly correlated with muscle $\mathrm{pH}$. Muscle $\mathrm{pH}$ has been utilized as a more objective means of determining dark-colored lean (Warris and Lister, 1983). True dark firm dry (DFD) beef is characterized by extremely dark color, very high muscle $\mathrm{pH}$ and lower than normal shear force values (Lawrie, 1992). The relationship between borderline dark cutting, and increased toughness found in the present study does not necessarily contradict previous research. Because borderline dark cutting was determined by visual means, the carcasses classified as 'dark' do not necessarily exhibit these true DFD characteristics. The $\mathrm{pH}$ of this population of cattle exhibited a relatively restricted $\mathrm{pH}$ range (5.35 to 5.79) (Wulf et al., 1997). Meat with intermediate $\mathrm{pH}$ values (5.8 to 6.2) have the highest shear force values (Bouton et al., 1973; Purchas, 1990). The current data correspond with these findings.

A potential hypothesis for temperament effects on tenderness may involve adrenaline action on $\beta$-adrenoceptors. Adrenaline binding at $\beta$-adrenergic receptors on muscle cell 
membranes mediate glycogen metabolism. Injection of $\beta$-adrenergic blocker prior to slaughter was successful in preventing dark-colored lean in sheep induced via adrenaline administration (Ashmore et al., 1974). $\beta$-adrenoceptor agonists have been implicated in increasing shear force values (Koohmaraie et al., 1991) and $\beta$-adrenoceptor density is mildly related to darkening of muscle color (Hoey et al., 1995). McVeigh and Tarrant (1981), however, found that an injection of a $\beta$-adrenoceptor blocker was not successful at preventing muscle glycogen depletion induced by physical activity. The difference in efficacy between method of dark cutter induction may be owing to differences in muscle fiber type and adrenaline affinity. From this we can postulate that a relationship between $\beta$ adrenoceptor density, or affinity, and temperament could possibly explain a portion of the effects on meat quality seen in the present study.

The current findings of a gender effect on tenderness does not agree with research by Prost et al. (1975) which found no gender based differences in tenderness. Another unexpected finding was that over $70 \%$ of the animals that exhibited borderline dark cutting were heifers. This differs from a study by Jones and Tong (1989) which found a higher incidence of dark cutting in steers than heifers. It does, however, agree with a study by Murray (1989), in which heifers had a higher incidence of dark cutting than steers. Murray (1989) proposed that the higher incidence of dark cutting in heifers was related to more rapid cooling of lighter heifer carcasses, and thus a slower decline in $\mathrm{pH}$.

Again, however, in the current study, gender is completely confounded by implant protocol. Observations by the second author in several large commercial slaughter plants indicate that the use of two or three trenbolone acetate implants in steers and hiefers may increase the incidence of dark cutters. Research by Vanderwert et al. (1985) and Baker and Gonyou (1986) shows that implantation with zeranol had no impact on agitation scores in steers or bulls. However, to the authors' knowledge no formal behavior-implant research has been conducted in heifers.

\section{CONCLUSIONS}

Temperament, or the excitability of cattle, had a significant impact on the incidence of borderline dark cutting in cattle. Animals that were more excitable had a greater tendency to exhibit borderline dark cutting at slaughter. Additionally, the temperament of cattle had a significant effect on subsequent carcass tenderness. Animals which were more excitable were also more likely to produce carcasses which exhibited shear force values of $3.9 \mathrm{~kg}$ or higher, which reduces the acceptability of the meat for use in food service establishments (Shackelford et al., 1991). These results imply that selecting for cattle with calm temperament may result in benefits in meat quality by indirect selection against stress susceptible animals.

\section{ACKNOWLEDGEMENTS}

This research was supported by the National Cattlemen's Beef Association, Englewood, CO 80155. The authors thank Deseret Cattle and Citrus Company in St. Cloud, Florida for their cooperation and assistance with our research.

\section{REFERENCES}

Addis, P. (1976) Follow up on stress resistance work. Proc. 60th Annual Meeting of Livestock Conservation Institute, 299 Livestock Exchange Bldg., St. Paul, MN, p. 119. 
Ashmore, C. (1974) Phenotypic expression of muscle fiber types and some implications to meat quality. Journal of Animal Science 38, 1158.

Ashmore, C., Carroll, F., Doerr, L., Tompkins, G., Stokes, H. and Parker, W. (1973) Experimental prevention of dark cutting meat. Journal of Animal Science 36, 33.

Baker, A. and Gonyou, H. (1986) Effects of zeranol implantation and late castration on sexual agonistic and handling behavior in male feedlot cattle. Journal of Animal Science 62, 1224.

Boissy, A. (1995) Fear and fearfulness in animals. Quarterly Review of Biology 70, 165.

Bouton, P., Carroll, F., Fisher, A., Harris, P. and Shorthose, W. (1973) Effect of altering ultimate $\mathrm{pH}$ on bovine muscle tenderness. Journal of Food Science 38, 816.

Bray, A., Graafhuis, A. and Chrystall, B. (1989) The cumulative effect of nutritional, shearing and pre-slaughter washing stresses on the quality of lamb meat. Meat Science 25, 59.

Crookshank, H., Elissalde, M., White, R., Clanton, D. and Smolley, H. (1979) Effect of handling and transportation of calves upon blood serum composition. Journal of Animal Science 48, 430.

Drugociu, G., Runceanu, L., Nicorici, R., Hritcu, V. and Pascal, S. (1977) Nervous typology of cows as a determining factor of sexual and productive behavior. Animal Breeding Abstracts 45, 1262.

Fordyce, G., Dodt, R. and Wythes, J. (1988) Cattle temperaments in extensive beef herds in northern Queensland. 1. Factors affecting temperament. Australian Journal of Experimental Agriculture 28, 683.

Gonyou, H., Hemsworth, P. and Barnett, J. (1986) Effects of frequent interactions with humans in growing pigs. Applied Animal Behavior Science 16, 269.

Grandin, T. (1979) The effect of pre-slaughter handling and penning procedures on meat quality. Journal of Animal Science 40, 147 (abstract).

Grandin, T. (1980) The effect of stress on livestock and meat quality prior to and during slaughter. International Journal for the Study of Animal Problems 1, 313.

Grandin, T. (1993) Behavioral agitation during handling of cattle is persistent over time. Applied Animal Behavior Science 36, 1.

Hargreaves, A. and Hutson, G. (1990) The effect of gentling on hear rate, flight distance and aversion of sheep to a handling procedure. Applied Animal Behavior Science 26, 243.

Hearnshaw, H. and Morris, C. (1984) Genetic and environmental effects on a temperament score in beef cattle. Australian Journal of Agriculture Research. 35, 723.

Hoey, A., Reich, M., Davis, G., Shorthose, R. and Sillence, M. (1995) $\beta_{2}$-Adrenoceptors densities do not correlate with growth, carcass quality, or meat quality in cattle. Journal of Animal Science 73, 3281.

Holmes, J., Ashmore, C. and Robinson, D. (1973) Effects of stress on cattle with hereditary muscular hypertrophy. Journal of Animal Science 36, 684.

Holmes, J., Robinson, D. and Ashmore, C. (1972) Blood lactic acid and behavior in cattle withhereditary muscular hypertrophy. Journal of Animal Science 35, 1011.

Johnson, D., Huffman, R., Williams, S. and Hargrove, D. (1990) Effects of percentage Brahman and Angus breeding, age-season of feeding and slaughter end point on meat palatability and muscle characteristics. Journal of Animal Science 68, 1980.

Jones, S. and Tong, A. (1989) Factors influencing the commercial incidence of dark cutting beef. Canadian Journal of Animal Science 69, 649.

Kenny, F. and Tarrant, P. (1987) The behavior of young Freisian bulls during social re-grouping at an abattoir. Influence of an overhead electrified wire grid. Applied Animal Behavior Science 18, 233.

Kenny, F. J. and Tarrant, P. V. (1988) Effect of oestrus behaviours on muscle glycogen concentration in dark cutting beef heifers. Meat Science 22, 21.

Koohmaraie, M., Shackelford, S., Muggli-Cockett, N. and Stone, R. (1991) Effect of the $\beta$-adrenergic agoinst $\mathrm{L}_{644,969}$ on muscle growth, endogenous proteinase activities, and postmortem proteolysis in wether lambs. Journal of Animal Science 69, 4823.

Lacourt, A. and Tarrant, P. (1985) Glycogen depletion patterns in myofibres of cattle during stress. Meat Science 15, 85.

Lawrie, R. (1958) Physiological stress in relation to dark cutting beef. Journal of the Science of Food and Agriculture 9, 721 .

Lawrie, R. (1992) The Chemistry of Muscle-Based Foods, eds E. Ledward, D. Johnston, and M. Knight, p. 43. Royal Society of Chemistry, Cambridge. 
Lyons, D. (1989) Individual differences in temperament of dairy goats and the inhibition of milk ejection. Applied Animal Behavior Science 22, 269.

McVeigh, J. and Tarrant, P. (1981) The breakdown of muscle glycogen during behavioral stress in normal and beta-adrenoceptor blocked young bulls. In The Problem of Dark-cutting in Beef. Current Topics of Veterinary Medicine and Animal Science, eds D. E. Hood and P. V. Tarrant, pp. 430-439. Martinus Niijhoff, The Hague, The Netherlands.

Murray, A. (1989) Factors affecting beef color at time of grading. Canadian Journal of Animal Science 69, 347.

O'Connor S., Tatum, J., Wulf, D., Green, R. and Smith, G. (1997) Genetic effects on beef tenderness in Bos indicus composite and Bos taurus cattle. Journal of Animal Science, (in press).

Pitts, F., Jr. (1971) Biochemical factors in anxiety neurosis. Behavioral Science 16, 82.

Prost, E., Pelczynska, E. and Kotula, A. (1975) Quality characteristics of bovine meat. II. Beef tenderness in relation to individual muscles, age and sex of animals and carcass quality grade. Journal of Animal Science 41, 541.

Purchas, R. (1990) An assessment of the role of $\mathrm{pH}$ differences in determining the relative tenderness of meat from bulls and steers. Meat Science 27, 129.

Rao, M. and Gault, N. (1989) The influence of fibre-type composition and associated biochemical characteristics on the acid buffering capacities of several beef muscles. Meat Science 26, 5.

SAS (1985) SAS User's Guide: Statistics (Version 5 Ed. ). SAS Inst. Inc., Cary, North Carolina, USA.

Selye, H. (1936) A syndrome produced by diverse noxious agents. Nature 138, 32.

Shackelford, S. D., Morgan, J. B., Cross, H. R. and Savell, J. W. (1991) Identification of threshold levels for Warner-Bratzler Shear force in beef loin steaks. Journal of Muscle Foods 2, 289.

Shrode, R. R. and Hammack, S. P. (1971) Chute behavior of yearling beef cattle. Journal of Animal Science 33, 193 (abstract).

Smith, G. Savell, J., Clayton, R., Field, T., Gill, D., Griffin, D., Hale, D., Miller, M., Montgomery, T., Morgan, J., Tatum, and Wise, J. (1992) The Final Report of the Blueprint for Total Quality Management in the Fed-Beef Industry: National Beef Quality Audit-1991. National Cattlemen's Association, Englewood, Colorado, USA.

Stricklin, W., Heisler, C. and Wilson, L. (1980) Heritability of temperament in beef cattle. Journal of Animal Science 51(1), 109 (abstract).

Tarrant, P. V. (1981) The occurrence, causes and economic consequences of dark cutting in beef-A survey of current information. In The Problem of Dark Cutting Beef, eds D. E. Hood and P. V. Tarrant, pp. 3-59. Martinus Niijhoff, The Hague, The Netherlands.

Tarrant, P. and Sherington, Journal (1980) An investigation of ultimate $\mathrm{pH}$ in the muscles of commercial beef carcasses. Meat Science 4, 287.

Tennessen, T. and Price, M. (1980) Pre-slaughter management and dark cutting in young bulls. Journal of Animal Science 51, 110 (abstract).

Tulloh, N. (1961) Behavior in cattle yards. II. A study of temperament. Animal Behavior 9, 25.

Tyler, R., Taylor, D. J., Cheffins, R. C. and Rickard, M. W. (1982) Bruising and muscle pH in zebu crossbred and British breed cattle. Veterinary Record 110, 444.

USDA (1988) Institutional meat purchase specifications for fresh beef. Agriculture Marketing Service, USDA, Washington, DC.

USDA (1989) Official United States standards for grades of carcass beef. Agricultural Marketing Service, USDA, Washington, DC.

Vanderwert, W., Berger, L., McKeith, F., Baker, A., Gonyou, H. and Bechtel, P. (1985) Influence of zeranol implants on growth, behavior and carcass traits in Angus and Limousin bulls andsteers. Journal of Animal Science 61, 310.

Voisinet, B., Grandin, T., Tatum, J., O'Connor, S. and Struthers, J. (1997) Feedlot cattle with calm temperaments have higher average daily gains than cattle with excitable temperaments. Journal of Animal Science 75, 892.

Warris, P. and Lister, D. (1983) Behavior and blood profile of bulls which produce dark cutting meat. Animal Production 36, 525 (abstract).

Whipple, G., Koohmaraie, M., Dikeman, M., Crouse, J., Hunt, M. and Klemm, R. (1990) Evaluation of attributes that affect longissimus muscle tenderness in Bos taurus and Bos indicus cattle. Journal of Animal Science 68, 2716. 
Wulf, D., O'Connor, S., Tatum, J. and Smith, G. (1997) Using objective measures of muscle color to predict beef longissimus tenderness. Journal of Animal Science 75, 684.

Young, O. and Foot, D. (1984) The biochemical basis of fibre types in bovine muscles. Meat Science 11, 123.

Zerouala, A. and Strickland, N. (1991) Cattle at risk for dark cutting beef have a higher proportion of oxidated muscle fibers. Meat Science 2A, 263. 